\title{
Time trends in primary-care morbidity, hospitalization and mortality due to pneumonia
}

\author{
A. B. VAN GAGELDONK-LAFEBER ${ }^{1 *}$, M. A. H. BOGAERTS ${ }^{2}$, R. A. VERHEIJ ${ }^{3}$ \\ AND M. A. B. VAN DER SANDE ${ }^{1}$ \\ ${ }^{1}$ National Institute for Public Health and the Environment (RIVM), Centre for Infectious Disease Control \\ Netherlands, Epidemiology and Surveillance Unit, Bilthoven, The Netherlands \\ ${ }^{2}$ Utrecht University, Institute for Risk Assessment Sciences, Utrecht, The Netherlands \\ ${ }^{3}$ Netherlands Institute for Health Services Research (NIVEL), Utrecht, The Netherlands
}

(Accepted 26 January 2009; first published online 4 March 2009)

\section{SUMMARY}

Most studies reporting pneumonia morbidity are restricted to hospitalized patients, although only a minority of pneumonia patients are admitted to hospital. To get a better understanding of the burden of disease in the general population, we conducted a population-based retrospective study to examine trends in pneumonia incidence in general practice, hospitalization, and mortality due to pneumonia in The Netherlands between 1997 and 2007. Between 2001/2002 and 2006/2007 there was an adjusted yearly increase of $12 \%$ in the clinical diagnosis of pneumonia in patients consulting general practitioners. Hospitalizations increased 5\% per year between 1999/2000 and $2006 / 2007$, while mortality annually decreased by $2 \%$ between $1997 / 1998$ and $2006 / 2007$. Our study suggests that the morbidity of pneumonia in the Dutch population increased considerably over this period, especially in primary-care settings, and that focusing only on hospitalization might underestimate the increasing public health burden of pneumonia.

Key words: Epidemiology, morbidity, mortality, pneumonia, primary care.

\section{INTRODUCTION}

Pneumonia, a common clinical disorder, is defined as an acute symptomatic inflammation of the lower respiratory tract whereby a new infiltrate is visible on a chest X-ray. However, in primary care the diagnosis is usually established on grounds of clinical criteria only [1-3]. Although chest X-ray is considered the gold standard for pneumonia diagnosis, it is only requested for about $20 \%$ of patients with a suspected

\footnotetext{
* Author for correspondence: A. B. van Gageldonk-Lafeber, M.Sc., National Institute of Public Health and the Environment, Epidemiology and Surveillance Unit, PO Box 1,3720 BA Bilthoven, The Netherlands.

(Email: rianne.van.gageldonk@rivm.nl)
}

lower respiratory tract infection in primary care [4]. Typical symptoms include cough, chest pain, fever, malaise and shortness of breath; crackles in the lungs are heard at auscultation [5]. Causes of pneumonia are diverse. Infection with microorganisms (bacteria, viruses, fungi or parasites) is most common, but pneumonia may also result from physical or chemical injury of the lungs. A distinction can be made between community-acquired pneumonia (CAP) and nosocomial pneumonia. CAP refers to infections acquired outside hospitals or nursing homes, whereas nosocomial pneumonia describes infections acquired in hospital settings or extended-care facilities.

Despite improved treatment strategies, pneumonia remains a major cause of morbidity and mortality in 
Western industrial countries [5-9]. Both morbidity and mortality of pneumonia are strongly related with age, with about $90 \%$ of all deaths due to pneumonia in industrial countries occurring within the $\geqslant 65$ years age group [5, 10-12]. In recent years, increasing trends of hospitalization due to pneumonia have been reported in the USA [10], Denmark [13], England [14] and The Netherlands [15], with a shifting of age distribution towards an elderly population offered as the major explanation.

Unfortunately these studies only address hospitalization, whereas admission to the hospital is needed for only $20-40 \%$ of all pneumonia patients [16]. Including data on general practitioner (GP) consultations, will therefore lead to a better understanding of the total burden of disease. We conducted a population-based retrospective study to assess recent trends in incidence of pneumonia in general practice, in hospitalization, and in mortality due to pneumonia in the Dutch population in the period between 1997 and 2007, adjusted for demographic changes in age and gender of the Dutch population.

\section{METHODS}

\section{Data sources}

To provide an overall insight in trends in pneumonia in The Netherlands, three datasets were studied for three different outcomes associated with pneumonia: GP consultations, hospital admissions, and mortality. The observed time period differs for the datasets because of the availability of the data.

\section{GP consultations}

Data from the Netherlands Information Network of General Practice (LINH), provided by the Netherlands Institute for Health Services Research (NIVEL), from May 2001 to April 2007 was used to investigate trends in the incidence of the clinical diagnosis of pneumonia in general practice. This data was recorded by on average 85 GP practices, with a total registered patient population of about 350000 patients (December 2004), representative of the Dutch population in respect of age, gender and type of insurance $[17,18]$. For every consultation, age, gender and the suspected diagnosis are recorded according to the International Classification of Primary Care (ICPC). In addition, referrals and prescribed medications are recorded. For this study we used data on
GP consultations for the clinical diagnosis of pneumonia (defined as ICPC R81) in combination with patients' age and gender. Because many patients with pneumonia consult their GP more than once for the same disease episode, we excluded repeated GP consultations within 90 days after the first pneumonia consultation in the data analyses. We regarded these excluded consultations as belonging to the same episode of pneumonia.

\section{Hospital admissions}

Data from the Dutch National Medical Register (LMR) from May 1999 to April 2007 was used to investigate trends in hospital admissions due to pneumonia. Data for all patients admitted to every general, teaching and specialized hospital in The Netherlands, registered at the patient's discharge were provided by the LMR and supplied by Prismant, the research and advisory agency for the Dutch Health Care Service [19]. Data include demographic characteristics of the patient as well as the principal and secondary diagnoses at hospital discharge, coded by ICD-9-CM codes (International Classification of Diseases, 9th revision-Clinical Modification). For this study pneumonia was defined as ICD-9-CM codes 003.22, 052.1, 055.1, 0.73.0, 083.0 and 480.XX487.XX (see Appendix A).

\section{Mortality}

The cause-of-death registry from Statistics Netherlands (CBS) from May 1997 to April 2007 was used to investigate trends in mortality due to pneumonia. CBS registers both primary and secondary causes of deaths per month, by 5-year age group and gender, based on the recent international classification of diseases (ICD-10). Pneumonia was defined as ICD-10 codes A15, A16, A48.1, A70, A78 and J12-J18 (see Appendix B).

\section{Statistical analysis}

Incidence of pneumonia in general practice was calculated as the number of incident cases with the clinical diagnosis of pneumonia per 1000 registered patients, using seven age groups $(0-4,5-14,15-24$, $25-44,45-64,65-74, \geqslant 75$ years). Incidence of hospitalized pneumonia and mortality due to pneumonia were assessed as respectively the number of patients with main discharge diagnosis pneumonia and the 
number of deceased with pneumonia as primary or secondary cause of death per 1000 inhabitants, using 5 -year age bands (i.e. $0-4,5-9,10-14, \ldots, \geqslant 95$ years).

The incidence and mortality of pneumonia fluctuates with the season, peaking in December and/or January in most years. This seasonal variation could influence annual trends when looking at calendar years. To correct for this we used so called 'respiratory years' for all analyses, defined as 1 May (year $n$ ) until 30 April (year $n+1$ ). Poisson regression was used to assess the yearly increase in incidence rates and mortality due to pneumonia per age group, adjusted for demographic changes in age and gender of the Dutch population. All statistical analyses were performed using SAS software version 9.1 (SAS Institute, USA).

\section{RESULTS}

\section{Pneumonia incidence in general practice}

Highest GP consultation rates because of (suspected) pneumonia were seen in the oldest $(\geqslant 65$ years) and the youngest ( $0-4$ years; Fig. $1 a)$ age groups. Between $2001 / 2002$ and 2006/2007 there was an increase in patients visiting their GP with a (suspected) pneumonia from $6 \cdot 0$ to $8 \cdot 8 / 1000$ registered patients (Table 1). Corrected for demographic changes in age and gender of the Dutch population, there is an adjusted increase of $12 \%$ (95\% CI 10-14) more patients consulting a GP for the clinical diagnosis of pneumonia every year, which represents a total increase of about $75 \%$ in the 5 -year study period. This increase was lowest in the 15-24 and 25-44 years age groups [respectively $7 \%$ per year $(95 \%$ CI 3-12) and $9 \%$ per year (95\% CI 5-13); Table 1].

\section{Hospital admissions}

Hospitalization because of pneumonia was most common in the youngest ( $0-4$ years) and the oldest age groups $(\geqslant 65$ years; Fig. $1 b)$. The number of patients hospitalized with a primary diagnosis of pneumonia increased from $1 \cdot 2$ to $1 \cdot 7 / 1000$ inhabitants in the period 1999/2000 to 2006/2007 (Table 2). After correcting for demographic changes, hospital admission for pneumonia increased $5 \%$ per year $(95 \%$ CI $4 \cdot 7-5 \cdot 9$ ), which represents a total increase of $44 \%$ for the observed period. This increase was lowest in the $0-4$ and $15-24$ years age groups [respectively 3\% per year $(95 \%$ CI $0 \cdot 5-6 \cdot 1)$ and $4 \%$ per year $(95 \%$ CI 1.6-5.5); Table 2].
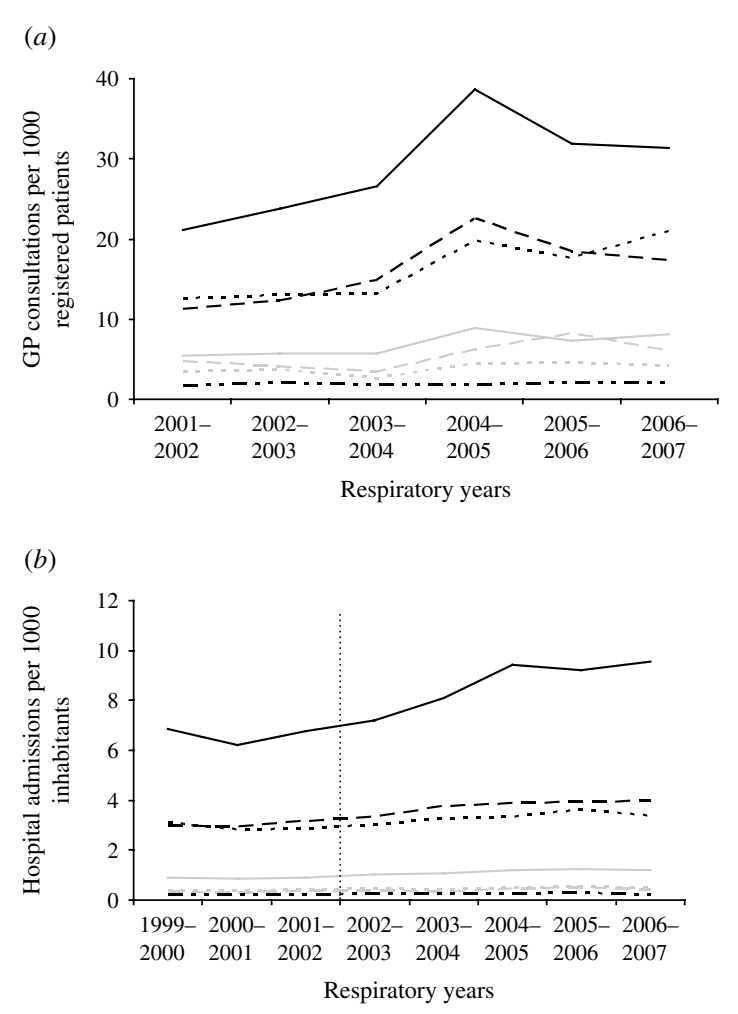

(c)

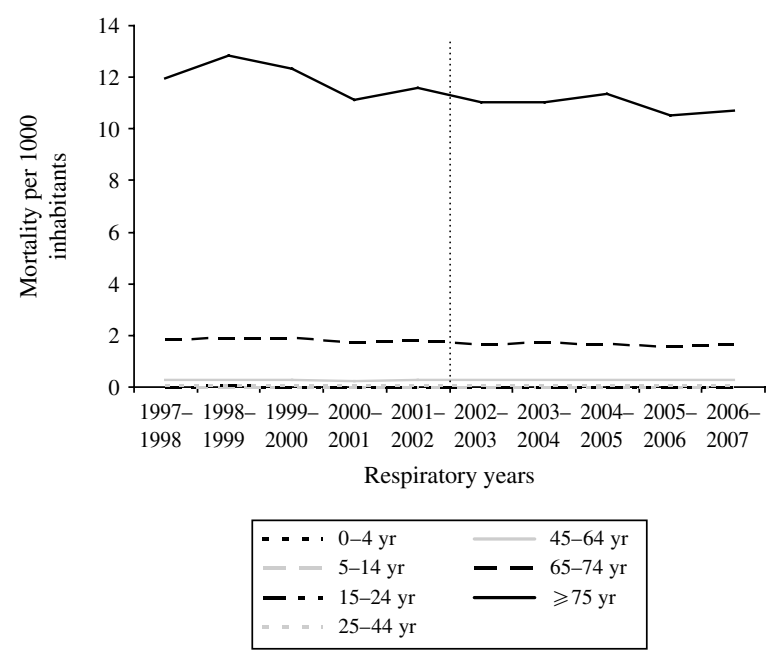

Fig. 1. Trends, by age group, for $(a)$ pneumonia incidence in general practice per 1000 registered patients for the period $2001 / 2002$ to $2006 / 2007$, (b) incidence of hospital admissions due to pneumonia per 1000 inhabitants for the period $1999 / 2000$ to $2006 / 2007,(c)$ incidence of mortality due to pneumonia per 1000 inhabitants for the period 1997/1998 to 2006/2007.

\section{Mortality}

Pneumonia-related mortality occurred mainly in persons aged $\geqslant 75$ years (Fig. 1c). Between 1997/1998 and $2006 / 2007$ mortality rates in the total population remained constant $(0 \cdot 9 / 1000$ inhabitants; Table 3). 
Table 1. Pneumonia incidence in general practice (GP) per 1000 registered patients, and adjusted increase per year for the period 2001/2002 to 2006/2007, by age group and gender

\begin{tabular}{lccccc}
\hline \hline & \multicolumn{2}{l}{$\begin{array}{l}\text { Pneumonia incidence in GP } \\
\text { per 1000 registered patients }\end{array}$} & & \multicolumn{2}{l}{$\begin{array}{l}\text { Adjusted increase } \\
\text { per year* }\end{array}$} \\
\cline { 2 - 3 } $\begin{array}{l}\text { Age group } \\
\text { (yr) }\end{array}$ & $2001 / 2002$ & $2006 / 2007$ & & $\%$ & $(95 \% \mathrm{CI})$ \\
\hline $0-4$ & $12 \cdot 7$ & $21 \cdot 0$ & $15 \cdot 9$ & $(8 \cdot 4-23 \cdot 9)$ \\
$5-14$ & $4 \cdot 8$ & $6 \cdot 1$ & $12 \cdot 3$ & $(6 \cdot 9-18 \cdot 4)$ \\
$15-24$ & $1 \cdot 7$ & $2 \cdot 1$ & $7 \cdot 3$ & $(2 \cdot 7-12 \cdot 1)$ \\
$25-44$ & $3 \cdot 4$ & $4 \cdot 2$ & $8 \cdot 8$ & $(4 \cdot 5-13 \cdot 4)$ \\
$45-64$ & $5 \cdot 4$ & $8 \cdot 2$ & $11 \cdot 5$ & $(7 \cdot 5-15 \cdot 6)$ \\
$65-74$ & $11 \cdot 3$ & $17 \cdot 5$ & $13 \cdot 6$ & $(9 \cdot 8-17 \cdot 5)$ \\
$\geqslant 75$ & $21 \cdot 2$ & $31 \cdot 4$ & $11 \cdot 1$ & $(6 \cdot 9-15 \cdot 5)$ \\
Total & $6 \cdot 0$ & $8 \cdot 8$ & $11 \cdot 9$ & $(10 \cdot 0-13 \cdot 7)$ \\
population & & & & \\
\hline \hline
\end{tabular}

CI, Confidence interval.

* Adjusted for demographic changes in age and gender of the Dutch population.

Table 2. Hospital admissions due to pneumonia per 1000 inhabitants and crude and adjusted increases per year for the period 1999/2000 to 2006/2007, by age group and gender

\begin{tabular}{|c|c|c|c|c|c|c|}
\hline \multirow{2}{*}{$\begin{array}{l}\text { Age group } \\
(\mathrm{yr})\end{array}$} & \multicolumn{2}{|c|}{$\begin{array}{l}\text { Hospital admissions } \\
\text { per } 1000 \text { inhabitants }\end{array}$} & \multicolumn{2}{|c|}{$\begin{array}{l}\text { Crude increase } \\
\text { per year }\end{array}$} & \multicolumn{2}{|c|}{$\begin{array}{l}\text { Adjusted increase } \\
\text { per year* }\end{array}$} \\
\hline & $1999 / 2000$ & $2006 / 2007$ & $\%$ & $(95 \% \mathrm{CI})$ & $\%$ & $(95 \% \mathrm{CI})$ \\
\hline $0-4$ & $3 \cdot 1$ & $3 \cdot 4$ & $3 \cdot 0$ & $(0 \cdot 3-5 \cdot 8)$ & $3 \cdot 2$ & $(0 \cdot 5-6 \cdot 1)$ \\
\hline $5-14$ & $0 \cdot 35$ & $0 \cdot 44$ & $6 \cdot 3$ & $(4 \cdot 4-8 \cdot 2)$ & $6 \cdot 1$ & $(4 \cdot 3-8 \cdot 0)$ \\
\hline $15-24$ & $0 \cdot 20$ & $0 \cdot 23$ & $4 \cdot 1$ & $(2 \cdot 2-6 \cdot 1)$ & $3 \cdot 5$ & $(1 \cdot 6-5 \cdot 5)$ \\
\hline $25-44$ & $0 \cdot 39$ & $0 \cdot 51$ & $4 \cdot 1$ & $(3 \cdot 0-5 \cdot 1)$ & $4 \cdot 7$ & $(3 \cdot 6-5 \cdot 7)$ \\
\hline $45-64$ & $0 \cdot 89$ & $1 \cdot 2$ & $8 \cdot 3$ & $(7 \cdot 4-9 \cdot 2)$ & $5 \cdot 8$ & $(5 \cdot 0-6 \cdot 7)$ \\
\hline $65-74$ & $3 \cdot 0$ & $4 \cdot 0$ & $6 \cdot 1$ & $(4 \cdot 9-7 \cdot 3)$ & $4 \cdot 9$ & $(3 \cdot 7-6 \cdot 1)$ \\
\hline$\geqslant 75$ & $6 \cdot 9$ & $9 \cdot 6$ & $8 \cdot 4$ & $(7 \cdot 3-9 \cdot 5)$ & $6 \cdot 2$ & $(5 \cdot 3-7 \cdot 2)$ \\
\hline $\begin{array}{l}\text { Total } \\
\text { population }\end{array}$ & $1 \cdot 2$ & $1 \cdot 7$ & $6 \cdot 6$ & $(6 \cdot 1-7 \cdot 2)$ & $5 \cdot 3$ & $(4 \cdot 7-5 \cdot 9)$ \\
\hline
\end{tabular}

CI, Confidence interval.

* Adjusted for demographic changes in age and gender of the Dutch population.

After adjusting for demographic changes in age and gender, a significant decrease in mortality rates was seen in all age groups, with the exception of the 45-64 years age group. This decrease was most pronounced in persons aged $<25$ years (Table 3 ). In the total population, mortality rates decreased by $2 \%$ a year (95\% CI $1 \cdot 7-2 \cdot 3)$, representing a total decrease of $17 \%$ for the observed period.

\section{DISCUSSION}

This study demonstrates that pneumonia is a great public health concern. Our population-based study is unique in including data on the clinical diagnosis of pneumonia in primary care. We demonstrated that the increasing trend in the incidence of the pneumonia in primary care is considerably steeper than the increasing trend in hospitalization due to pneumonia. Earlier studies addressing only hospitalization might have underestimated the total public health burden of pneumonia.

Both the pneumonia incidence in general practice and the yearly increase in hospitalization was high in the youngest $(0-4$ years) and oldest ( $\geqslant 65$ years) age groups. Hospital admission because of pneumonia was also high in these age groups, while the yearly 
Table 3. Mortality due to pneumonia per 1000 inhabitants and crude and adjusted increases per year for the period 1997/1998 to 2006/2007, by age group and gender

\begin{tabular}{|c|c|c|c|c|c|c|}
\hline \multirow{2}{*}{$\begin{array}{l}\text { Age group } \\
(\mathrm{yr})\end{array}$} & \multicolumn{2}{|c|}{$\begin{array}{l}\text { Mortality per } \\
1000 \text { inhabitants }\end{array}$} & \multicolumn{2}{|c|}{$\begin{array}{l}\text { Crude increase } \\
\text { per year }\end{array}$} & \multicolumn{2}{|c|}{$\begin{array}{l}\text { Adjusted increase } \\
\text { per year* }\end{array}$} \\
\hline & $1997 / 1998$ & $2006 / 2007$ & $\%$ & $(95 \% \mathrm{CI})$ & $\%$ & $(95 \% \mathrm{CI})$ \\
\hline $0-4$ & 0.035 & $0 \cdot 024$ & $-5 \cdot 1$ & $(-8 \cdot 9$ to $-1 \cdot 1)$ & $-5 \cdot 3$ & $(-9 \cdot 1$ to $-1 \cdot 4)$ \\
\hline $5-14$ & $0 \cdot 016$ & $0 \cdot 011$ & $-4 \cdot 8$ & $(-9 \cdot 1$ to $0 \cdot 4)$ & $-5 \cdot 4$ & $(-9.6$ to -1.0$)$ \\
\hline $15-24$ & $0 \cdot 014$ & $0 \cdot 010$ & $-4 \cdot 4$ & $(-8 \cdot 2$ to $-0 \cdot 4)$ & $-4 \cdot 6$ & $(-8 \cdot 4$ to $-0 \cdot 7)$ \\
\hline $25-44$ & 0.036 & 0.028 & $-3 \cdot 3$ & $(-5 \cdot 1$ to $-1 \cdot 6)$ & $-3 \cdot 4$ & $(-5 \cdot 2$ to $-1 \cdot 6)$ \\
\hline $45-64$ & $0 \cdot 275$ & $0 \cdot 277$ & $1 \cdot 8$ & $(1 \cdot 1$ to $2 \cdot 6)$ & $-0 \cdot 7$ & $(-1 \cdot 4$ to $0 \cdot 1)$ \\
\hline 65-74 & 1.877 & $1 \cdot 660$ & $-1 \cdot 0$ & $(-1.7$ to -0.3$)$ & $-2 \cdot 0$ & $(-2.7$ to -1.4$)$ \\
\hline$\geqslant 75$ & $11 \cdot 96$ & $10 \cdot 72$ & $-0 \cdot 1$ & $(-0 \cdot 7$ to $0 \cdot 6)$ & $-2 \cdot 1$ & $(-2 \cdot 6$ to $-1 \cdot 6)$ \\
\hline Total population & $0 \cdot 9$ & $0 \cdot 9$ & $-0 \cdot 1$ & $(-0.5$ to $0 \cdot 2)$ & $-2 \cdot 0$ & $(-2 \cdot 3$ to $-1 \cdot 7)$ \\
\hline
\end{tabular}

CI, Confidence interval.

* Adjusted for demographic changes in age and gender of the Dutch population.

increase of hospitalization in older persons $(6 \%)$ was higher than in younger persons ( $3 \%)$.

In 2006 and 2007, LMR reported a (temporarily) lower coverage of hospitals reporting their discharge data. Still, we found that the incidence of hospitalized pneumonia in 2005/2006 and 2006/2007 was almost similar with that in 2004/2005. The increase in hospitalization found in our study might therefore be slightly underestimated.

The rising incidence of pneumonia seems to involve age groups in addition to the youngest and oldest, since substantial increases in the incidence of clinical diagnosis in general practice $(>10 \%)$ and in hospitalization $(>5 \%)$ were seen in the 5-14 and 45-64 years age groups for men and women.

The shift of age distribution towards an elderly population did not fully explain the rising morbidity, because we found increasing trends despite adjustment for demographic changes in the age of the Dutch population.

In contrast with the increasing trend in the incidence of the clinical diagnosis pneumonia in primary care and hospitalization due to pneumonia, we found a slightly decreasing trend in mortality after adjustment for demographic changes in the age and gender of the Dutch population.

Our results in respect of hospitalization and mortality are consistent with recent trends found in Denmark, England and USA [10, 13, 14]. In Denmark, incidence of hospital admissions increased by $50 \%$ between 1994 and 2003, whereas relative in-hospital mortality within 30 days after the admission data decreased by $11 \%$ [13]. Incidence of hospitalized pneumonia in the elderly in the USA increased by $20 \%$ from 1988-1990 to 2000-2002, and in-hospital mortality remained constant [10]. In England a 34\% increase in the incidence of hospital admissions for pneumonia was seen in recent years [14]. A study on pneumonia-related mortality in The Netherlands reported an increase since 1990, although there seems to be a decreasing trend towards the end of the study period (1999-2002) [15]. Our results suggest this decreasing trend in pneumonia mortality has continued. Our findings are not completely comparable with the results of Oosterheert et al. [15], as we used 'respiratory years' instead of calendar years.

As previously mentioned, demographic changes do not fully explain the rising morbidity. However, a higher prevalence of chronic diseases due to an ageing population and altered lifestyles might partially explain our findings $[10,13,20]$. The purpose of this study was to explore current trends and there was no possibility to look at comorbidity in all three datasets. The GP dataset does hold this information, making it an interesting option for future research.

There are several other possible explanations for the increasing incidence of clinical diagnosis of pneumonia in primary care and the increasing trend for hospitalization with somewhat declining mortality due to pneumonia. The increase in incidence of GP consultations might be a result of a change of behaviour in regard to seeking medical care in the general population. In that case we would also expect an increase in the total number of GP consultations over the past years. However, the overall frequency of GP consultation in The Netherlands was more or less 
stable over the observation period [1,8]. Moreover, the increase in hospitalized pneumonia argues against a behavioural change being the main explanation.

The increase in hospitalization might be caused by changes in the policy regarding admission of patients or by treatment strategies. In general, patients with pneumonia in The Netherlands are treated in the ambulatory setting. According to the national guidelines, only patients with severe CAP or antibiotic treatment failure are referred to hospital [1]. There have been no specific alterations in these guidelines in the recent years that could account for the increase in hospitalization found in our study.

Another possible explanation for the increasing incidence of morbidity but decreasing mortality of pneumonia is variation in the pathogens causing pneumonia. Both changes in the prevalence of pathogens and changes in the virulence of specific pathogens might have caused a higher pathogenicity but lower mortality. These changes might be a result of recent strategies to reduce antibiotic prescriptions. However, the Dutch antibiotic prescribing rates are already low compared with other European countries and the USA and remained almost constant over the past decade [21, 22].

A limitation of our ecological study is the use of three datasets that do not consist of completely the same type of patients. Moreover, the existence of potential shifts in other respiratory diagnoses was not covered by our study. The comparison between the databases must therefore be interpreted with some caution, but is not expected to affect the overall increasing trend in the incidence of pneumonia in primary care and in hospitalization.

The apparent peak in GP consultations for pneumonia in 2004/2005 is probably related to the relatively high incidence of influenza that year, since pneumonia is a common complication of influenza infection [23]. On the contrary some of the influenza patients might be misclassified as pneumonia cases. The diagnosis pneumonia was based on registered codes, whereas no information was available on clinical symptoms and/or the presence of infiltrative abnormalities on chest X-ray, another limitation of our study. This might also have resulted in some misclassification of other illnesses presenting with similar symptoms, e.g. bronchitis [24]. In addition, a recent study showed that the overall sensitivity for detecting CAP with the ICD-CM codes, which are used in the LMR dataset, is modest ( $72 \cdot 4 \%$ ) [25]. However, there is no reason to believe that the extent of both types of misclassification changed during the observed period, and it is therefore not expected to affect the increasing trend in morbidity.

In conclusion, our study showed that focusing only on hospitalization conceals the increasing public health burden of pneumonia in the general population. Future studies would benefit from linking GP, hospital and mortality data by individual patient. This would allow the investigation of possible changes in primary care treatment of and referral rates for pneumonia that might underlie these changes.

\section{APPENDIX A}

\section{List of pneumonia-related ICD-9-CM codes (International Classification of Diseases, 9th revision - Clinical Modification)}

\begin{tabular}{ll}
\hline \hline $\begin{array}{l}\text { ICD-9-CM } \\
\text { code }\end{array}$ & Explanation \\
\hline 003.22 & Salmonella pneumonia \\
052.1 & Varicella with (haemorrhagic) pneumonia \\
055.1 & Post-measles pneumonia \\
073.0 & Ornithosis with pneumonia \\
0830.0 & Q fever \\
$480 . \mathrm{XX}$ & Viral pneumonia \\
481 & Pneumococcal pneumonia (Streptococcus \\
& pneumoniae) \\
$482 . \mathrm{XX}$ & Other bacterial pneumonia \\
483 & Pneumonia due to other specified organism \\
$484 . \mathrm{XX}$ & Pneumonia in infectious diseases classified \\
& elsewhere \\
485 & Bronchopneumonia, organism unspecified \\
486 & Pneumonia, organism unspecified \\
$487 \cdot 0$ & Influenza with pneumonia \\
\hline \hline
\end{tabular}

\section{APPENDIX B}

\section{List of pneumonia-related ICD-10 codes (International Classification of Diseases, 10th revision)}

\begin{tabular}{ll}
\hline \hline $\begin{array}{l}\text { ICD-10 } \\
\text { code }\end{array}$ & Explanation \\
\hline A15 & $\begin{array}{l}\text { Respiratory tuberculosis, bacteriologically and } \\
\text { histologically confirmed }\end{array}$ \\
A16 & $\begin{array}{l}\text { Respiratory tuberculosis, not confirmed } \\
\text { bacteriologically or histologically }\end{array}$ \\
A48.1 & $\begin{array}{l}\text { Legionnaires' disease } \\
\text { A70 }\end{array}$ \\
A78 & $\begin{array}{l}\text { Vittacosis } \\
\text { J12 }\end{array}$ \\
J13 & $\begin{array}{l}\text { Viral pneumonia, not elsewhere classified } \\
\text { Pneumia due to Streptococcus pneumoniae }\end{array}$
\end{tabular}




\section{APPENDIX B (cont.)}

\begin{tabular}{ll}
\hline \hline $\begin{array}{l}\text { ICD-10 } \\
\text { code }\end{array}$ & Explanation \\
\hline J14 & Pneumonia due to Haemophilus influenzae \\
J15 & $\begin{array}{l}\text { Bacterial pneumonia, not elsewhere classified } \\
\text { J16 }\end{array}$ \\
$\begin{array}{c}\text { Pneumonia due to other infectious organisms, } \\
\text { not elsewhere classified }\end{array}$ \\
J17 & $\begin{array}{l}\text { Pneumonia in disease classified elsewhere } \\
\text { J18 }\end{array}$ \\
\hline
\end{tabular}

\section{ACKNOWLEDGEMENTS}

We thank the following persons for their cooperation in supplying the data concerning this article: A. van der Meulen, M.Sc. (CBS), W. F. Hoogen Stoevenbeld (Prismant, LMR) and all the general practitioners participating in LINH.

\section{DECLARATION OF INTEREST}

None.

\section{REFERENCES}

1. Schouten JA, et al. Revised SWAB guidelines for antimicrobial therapy of community-acquired pneumonia. The Netherlands Journal of Medicine 2005; 63: 323-335.

2. NHG Standaard. M78: Acuut hoesten. NHG 2003. (http://nhg.artsennet.nl/upload/104/standaarden/M78/ start.htm). Accessed July 2008.

3. Metlay JP, Fine MJ. Testing strategies in the initial management of patients with community-acquired pneumonia. Annals of Internal Medicine 2003; 138: 109-118.

4. Woodhead M, et al. Use of investigations in lower respiratory tract infection in the community: a European survey. European Respiratory Journal 1996; 9: 15961600.

5. Cassiere HA, Niederman MS. Community-acquired pneumonia. Disease-a-Month 1998; 44: 613-675.

6. Jackson ML, et al. The burden of community-acquired pneumonia in seniors: results of a population based study. Clinical Infectious Diseases 2004; 39: 1642-1650.

7. File TM. Community-acquired pneumonia. Lancet 2003; 362: 1991-2001.

8. Brown PD, Lerner SA. Community-acquired pneumonia. Lancet 1998; 352: 1295-1302.

9. Ochoa-Gondar O, et al. The burden of communityacquired pneumonia in the elderly: the Spanish EVAN65 study. BMC Public Health. 2008 27; 8: 222.
10. Fry AM, et al. Trends in hospitalizations for pneumonia among persons aged 65 years or older in the United States, 1988-2002. Journal of the American Medical Association 2005; 294: 2712-2719.

11. Meyer KC. Lung infections and aging. Ageing Research Reviews 2004; 3: 55-67.

12. Statistics Netherlands. Statline (http://statline.cbs.nl/ statweb/). Accessed July 2008.

13. Thomsen RW, et al. Rising incidence and persistently high mortality of hospitalized pneumonia: a 10-year population-based study in Denmark. Journal of Internal Medicine 2006; 259: 410-417.

14. Trotter CL, et al. Increasing hospital admissions for pneumonia, England. Emerging Infectious Diseases 2008; 14: 727-733.

15. Oosterheert JJ, et al. The increase in pneumonia-related morbidity and mortality among adults in the Netherlands and possible explanations for it [in Dutch]. Nederlands Tijdschrift voor Geneeskunde 2004; 148: 1765-1769.

16. Hoare Z, Lim WS. Pneumonia: update on diagnosis and management. British Medical Journal 2006; 332: 1077-1079.

17. Braspenning J, Wichers L, Faber M. Management of the LINH GP practices is representative [in Dutch]. Huisarts \& Wetenschap 2007; 50: 133.

18. NIVEL. Facts and figures about general practitioner care in the Netherlands (http://www.linh.nl/). Accessed July 2008.

19. Dutch National Medical Register (LMR)-Prismant (http://www.prismant.nl/informatieproducten/). Accessed July 2008.

20. Kemper HCG, Stasse-Wolthuis M, Bosman W. The prevention and treatment of overweight and obesity: Summary of the advisory report by the Health Council of the Netherlands. The Netherlands Journal of Medicine 2004; 62: 10-17.

21. Kuyvenhoven MM, Van Balen FAM, Verheij TJM. Outpatient antibiotic prescriptions from 1992 to 2001 in The Netherlands. Journal of Antimicrobial Chemotherapy 2003 ; 52: 675-678.

22. Prins JM, et al. Experiences with the Dutch Working Party on Antibiotic Policy (SWAB). Eurosurveillance 2008; 13.

23. Dijkstra F, et al. Long time trends in influenza-like illness and associated determinants in The Netherlands. Epidemiology and Infection. Published online: 15 September 2008. doi:10.1017/S095026880800126X.

24. Speets AM, et al. Chest radiography and pneumonia in primary care: diagnostic yield and consequences for patient management. European Respiratory Journal 2006; 28: 933-938.

25. Van de Garde MW, et al. International classification of diseases codes showed modest sensitivity for detecting community-acquired pneumonia. Journal Clinical Epidemiology 2007; 60: 834-838. 